\title{
Daily step counts and selected biological and psychological variables in 16-18-year-old girls
}

\footnotetext{
Authors' Contribution:

A - Study Design

B - Data Collection

C - Statistical Analysis

D - Data Interpretation

E - Manuscript Preparation

F - Literature Search

G - Funds Collection
}

\author{
Adam Kantanista ${ }^{\text {ABDEFG }}$, Pawel Lisowski ${ }^{\text {BCDEF }}$, Agata Glapa ${ }^{\text {BEF }}$ \\ University School of Physical Education in Poznan, Poland \\ Department of the Methodology of Physical Education
}

Key words: physical activity, step counts, adolescence, girls, psychological and biological variables.

Material/Methods: The study included data from 60 girls, aged 16-18. Voluntary participants were selected from a public high school in Poland. Number of steps was measured with a pedometer Yamax Digi-Walker, model SW 701, during 7 days. Girls were classified into three groups: low active, slightly active and active (5,000-7,499; 7,500-9,999; $\geq 10,000$ steps/day, respectively). The levels of psychological factors were determined by means of a questionnaire survey. Estimated $\mathrm{VO}_{2}$ max was assessed by a 1-mile walk test. The percentage of body fat and lean body mass was evaluated using Bodystat 1,500, bio-impedance method.

Results: Analysis of variance showed no statistically significant differences in the biological and psychological variables among low active, slightly active and active girls.

Conclusions: Girls in the study performed approximately from 5,000 to 12,500 steps a day. To explain better relationships between daily step counts and psychological and biological variables future research should additionally involve girls with less than 5,000 steps a day and more than 12,500 steps a day.

Word count: 2,378

Tables: 1

Received: May 2013

Figures: 1

Accepted: March 2014

References: 35

Published: March 2014

Corresponding author:

Dr Adam Kantanista

University School of Physical Education in Poznań

61-871 Poznań, ul Królowej Jadwigi 27/39

Phone: +4861 8355204

E-mail: adam.kantanista@gmail.com 


\section{Introduction}

Physical inactivity is the basic reason for the health-worsening and even health-damaging outcomes [1]. Conversely, regular physical activity (PA) is an essential biological stimulus that is needed to maintain the structures and functions of organs and reduces the risk of a number of adverse health outcomes, including cardiovascular disease mortality, hypertension, colon cancer and diabetes [2, 3, 4]. Furthermore, the risk of insufficient PA is greater in girls than in boys, especially during adolescence [4].

PA is also widely promoted for maintaining proper body weight and reducing levels of obesity, which occurs as a result of imbalance in the body between energy intake and energy expenditure. Research carried out in recent years in Poland indicates that about 5 percent of 15 to 19-year-old girls are overweight or obese [5]. This data largely confirmed the Health Behaviour of School-Aged Children report, indicating that overweight and obesity affect 7 to 11 percent of girls aged 15-18 [6]. A similar study conducted in the United States estimated that among 12- to 19-year-old girls more than 15 percent are overweight or obese [7].

Studies indicate a significant relationship between the level of PA and the level of fatness [8] and that increasing PA expressed as energy expended is positively related to reductions in total adiposity [9]. PA is determined by many variables. In the Van der Horst et al. [10] review of correlates of PA in youth, self-efficacy, parental education, attitude, goal-orientation/motivation, family influences and support from friends were all indicated. Additionally, BMI, depression, ethnicity, the socioeconomic status and parental education were associated with adolescents' sedentary behaviour and insufficient PA.

Researchers and practitioners have used pedometers in different settings (e.g. local communities, schools) to assess and motivate PA behaviours because they are simple and inexpensive body-worn motion sensors [11]. Based on previous studies and programmes using pedometers, researchers have proposed the establishment of certain standards for the daily number of steps. For example, the general assumptions given by Tudor-Locke and Bassett [12] and Tudor-Locke et al. [13] determine the number of steps below 5,000 as a sedentary lifestyle, while the number of steps between 5,000 and 7,499 indicates a low activity. Recordings of between 7,500 and 9,999 steps per day are characterized as slightly active, while people taking a greater a number of steps (between 10,000 and 12,499) are classified as active. The last level highly activity - characterized people taking over 12,500 steps a day. Apart from step counts, there are other PA recommendations. The proposals of both the World Health Organization [14] and the EU [15] involve at least 60 minutes of moderate to vigorous-intensity PA per day for children and adolescents. In the case of walking, only brisk ones fulfil this condition.

One of the most important observations in previous pedometer-based research is that girls take significantly fewer steps than boys $[16,17]$. Pedometers were used to assess the level of PA of Polish adolescents [18,19]; however, according to our knowledge, the data describing relationships between daily step counts and biological and psychological variables in Polish adolescents are limited. In the current study, three different correlates of PA was taken into consideration. Self-efficacy is one of the main contributors to behavior change and occurs in theoretical models in PA. Body image and PA enjoyment are not directly included as an influential psychosocial construct in theories and models used in behavioral and social science research on PA [20]. Research indicated positive relationships between body image and PA [21], yet relationships between PA enjoyment and PA in adolescents are inconclusive [10].

The aim of this study was to assess the relationship between the number of steps a day and biological (body fat, lean body mass, $\mathrm{BMI}$ and estimated $\mathrm{VO}_{2}$ max) and psychological (self-efficacy, enjoyment of PA and self-perception of body image) factors in 16-18-year-old girls.

\section{Material and methods}

\section{Participants}

The study included data from 60 girls, aged 16-18 $(M=17.3 \pm 0.98)$. Voluntary participants were selected from a public high school in Poland. The study protocol was approved by the Local 
Bioethics Committee of the Karol Marcinkowski University of Medical Sciences in Poznan (decision no. 893/12). Written assent from all participants and consent from parents of minors were obtained.

Students taking part in the study wore a pedometer all the time during 7 days, excluding the time for sleeping, swimming and physical education. The number of steps was measured with a Yamax Digi-Walker SW 701 pedometer. Girls were classified into three groups according to the mean value of steps taken during the day: 1) 5,000-7,499 steps/day was the low active group $(n=22)$; 2) 7,500-9,999 steps/day was the slightly active group $(n=19)$; and 3$) \geq 10,000$ steps/day indicates the point that should be used to classify individuals as active $(n=19)$. Classification was based on the proposals by Tudor-Locke and Bassett' [12] and Tudor-Locke et al. [13]. Because of a lack of data there was no group of girls with basal activity $(<2,500$ steps/day), limited activity (2,500-4,999 steps/day) and high activity ( $\geq 12,500$ steps/day).

\section{Biological variables measurement}

Estimated $\mathrm{VO}_{2}$ max

To estimate $\mathrm{VO}_{2}$ max a 1-mile walking test (Rockport Fitness Walking Test) was carried out. The test was held in a sports hall. After the test, the participants measured their own heart rates through the palpation method. The data was used to estimate $\mathrm{VO}_{2}$ max by the following formula $[22,23]$ :

$\mathrm{VO}_{2} \max =132.853-(0.0769 \times$ body mass in pounds $)-(0.3877 \times$ age in years $)+(6.315 \times$ sex for girls "0") - (3.2649 $\times$ walk time in minutes $)-(0.1565 \times$ heart rate $)$.

\section{Body compositions}

Using Bodystat 1500, bio-impedance method, the percentage of body fat (BF) and lean body mass (LBM) were measured. In addition, the results of the measurements of body mass and height were used to calculate BMI. Weight was measured with a set of Seca 761 scales in light clothing (without shoes) to the nearest $0.5 \mathrm{~kg}$. While the height was measured with a tape to the nearest $0.5 \mathrm{~cm}$.

\section{Psychological variables measurement \\ Self-efficacy}

Self-efficacy was assessed using the Self-Efficacy Questionnaire [24]. The questionnaire consisted of eight items, e.g. I can be physically active during my free time on most days. A 3-point Likert scale was used with response options: I agree, I neither agree nor disagree and I disagree. It was possible to obtain 24 points in total on this scale. Evidence for the factorial validity and the invariance of the questionnaire was provided [24]. The internal consistency of the scale was established with the Cronbach's Alpha test, and it was $\alpha=0.71$.

\section{Enjoyment of physical activity}

A Physical Activity Enjoyment Scale was used to assess enjoyment of PA [25]. It consisted of 16 items, e.g. When I am active: I feel bored, I enjoy it. A 5-point Likert scale was used with the potential response from I disagree a lot to I agree a lot. It was possible to obtain a maximum of 80 points on this scale. The factorial validity and the construct validity indicate that the Physical Activity Enjoyment Scale is a valid measure of physical activity enjoyment among adolescent girls [25]. The internal consistency of the scale was established with the Cronbach's Alpha test, and it was $\alpha=0.90$.

\section{Self-perception of body image}

The self-perception of body image was assessed using the Body Image Subscale (BIS) included in the Body Investment Scale developed by Orbach and Mikulincer [26]. The BIS comprises six statements each scored in a 5 -item scale ranging from absolutely disagree to absolutely agree (corresponding to between 0 and 4 points). Consequently, the maximum global BIS score is 24 points. Evidence for the validity of the scale was provided [26]. In the research 
conducted in Poland, this scale featured a high reliability with Cronbach's alpha reliability coefficient at 0.85 , and one factor accounting for $58 \%$ of total variance [31].

\section{Statistical analysis}

Mean (M) and standard deviation (SD) were calculated for each variable. Differences between the groups were tested with One-way ANOVA. To conduct detailed multiple comparisons the Tuckey's HSD post-hoc test was employed. The level of significance was set at $p<.05$. Statistical calculations were performed by using the Statistica 10 software package.

\section{Results}

The mean value of steps taken by the girls qualified for three groups was: low active $(\mathrm{M}=5,792.7$ steps/day), slightly active $(\mathrm{M}=8,663.3$ steps/day) and active $(\mathrm{M}=12,413.7$ steps/day) (Fig. 1). Analysis of variance indicated differences among the groups $F(2,57)=93.8$, $p<.000$. Post-hoc analysis showed differences among all groups, $p<.000$.

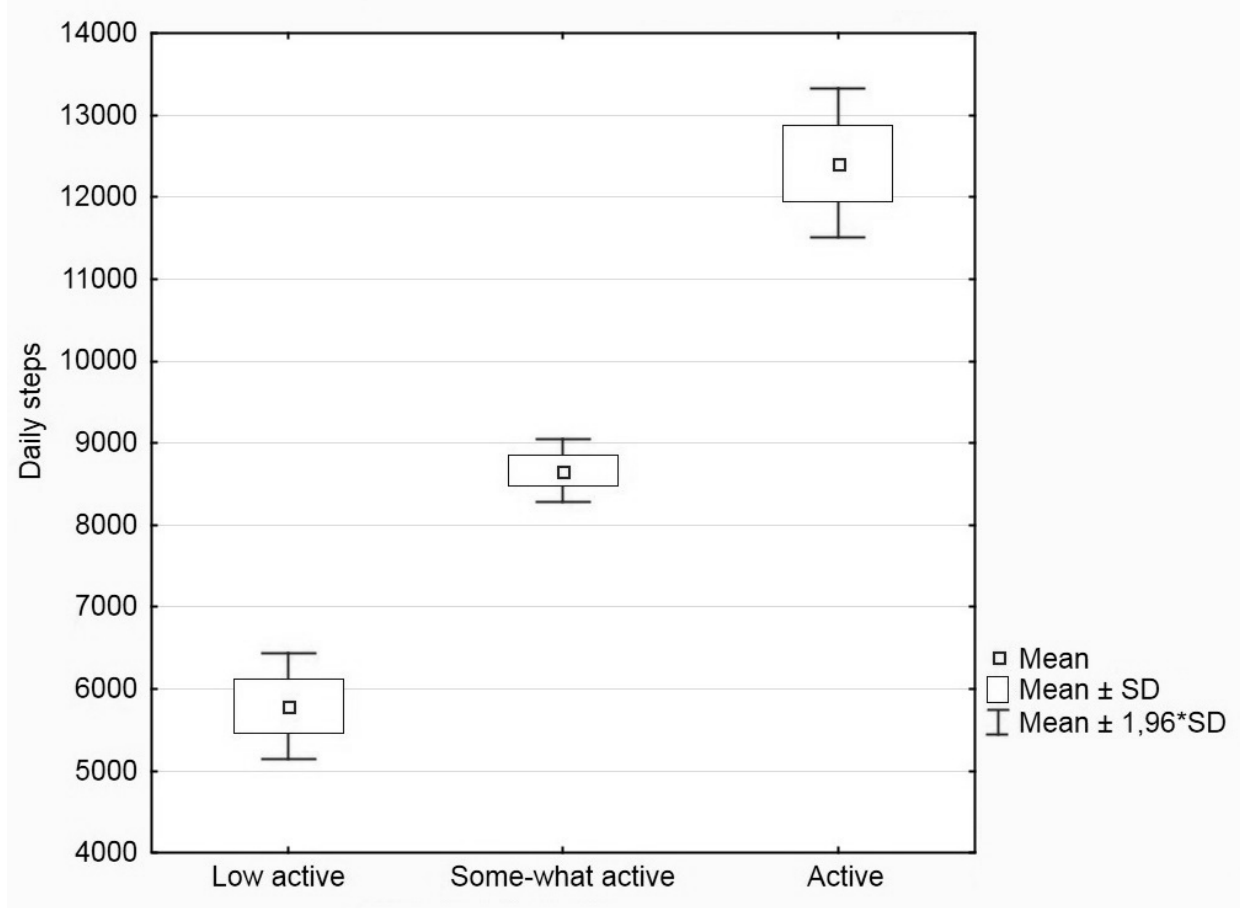

Fig. 1. Daily step counts in low active, slightly active and active girls

Table 1 shows the mean values of biological and psychological variables obtained from the girls with different levels of PA. Analysis of variance showed no statistically significant differences in the studied variables. However, in terms of biological variables, active girls achieved the highest average level for the estimated $\mathrm{VO}_{2}$ max and LBM and the lowest mean values of $\mathrm{BF}$ and $\mathrm{BMI}$.

Analysis of variance indicated that in terms of the psychological variables, there were no differences between the groups of low active, slightly active and active girls. The highest average value of self-efficacy was achieved by the group of active girls, while the highest levels of enjoyment of PA and self-perception of body image were recorded for the group of slightly active girls. 
Tab. 1. Mean scores, standard deviations values and differences among low active, slightly active and active girls in biological and psychological variables

\begin{tabular}{|c|c|c|c|c|c|}
\hline Variable & $\begin{array}{c}\text { Low active girls } \\
n=22 \\
M \pm S D\end{array}$ & $\begin{array}{c}\text { Slightly active girls } \\
n=19 \\
M \pm S D\end{array}$ & $\begin{array}{c}\text { Active girls } \\
n=19 \\
M \pm S D\end{array}$ & $\mathrm{~F}$ & $\mathrm{p}$ \\
\hline \multicolumn{6}{|l|}{ Biological } \\
\hline $\begin{array}{l}\text { Estimated } \mathrm{VO}_{2} \max \\
(\mathrm{ml} / \mathrm{kg} / \mathrm{min})\end{array}$ & $47.3 \pm 4.8$ & $47.4 \pm 5.2$ & $49.5 \pm 2.8$ & 1.60 & .21 \\
\hline $\mathrm{BF}(\%)$ & $27.7 \pm 6.5$ & $28.3 \pm 7.5$ & $25.5 \pm 4.6$ & 1.05 & .36 \\
\hline LBM (\%) & $72.3 \pm 6.5$ & $71.7 \pm 7.5$ & $74.5 \pm 4.5$ & 1.05 & .36 \\
\hline $\mathrm{BMI}(\mathrm{kg} / \mathrm{m} 2)$ & $22.3 \pm 4.9$ & $22.8 \pm 6.7$ & $21.3 \pm 2.9$ & .46 & .63 \\
\hline \multicolumn{6}{|l|}{ Psychological } \\
\hline Enjoyment of PA (pts) & $54.8 \pm 20.9$ & $63.1 \pm 10.4$ & $56.2 \pm 21.7$ & 1.12 & .33 \\
\hline Self-efficacy (pts) & $19.5 \pm 5.0$ & $18.7 \pm 2.9$ & $20.3 \pm 2.3$ & .93 & .40 \\
\hline Self-perception of body image (pts) & $20.1 \pm 7.1$ & $21.4 \pm 5.4$ & $19.8 \pm 5.9$ & .37 & .69 \\
\hline
\end{tabular}

\section{Discussion}

With increasing urbanization and modernization there has been an increase in the prevalence of obesity which can be attributed to reduced levels of PA [27]. An insufficient level of PA has been observed more often in girls [17]. Therefore, the aim of our study was to assess the relationship between the number of steps per day and selected biological and psychological factors in 16-18year-old girls. From among different recommendations concerning daily step numbers, the proposals of Tudor-Locke and Bassett [12] and Tudor-Locke et al. [13] were chosen.

The results obtained in the study indicate a lack of significant differences in biological variables among low active, slightly active and active girls. However, it is worth noting that the active girls had the highest average $\mathrm{VO}_{2}$ max and LBM, and the lowest level of BF and BMI. An inverse relationship between daily steps counts and BMl was observed in a study by Cuddihy et al. [28]. In turn, Taverno et al. [29], in research on 15-year-old girls, found that highly active adolescent girls had lower BMI and BF and were less sedentary when compared with those who were less active. However, in that research accelerometers were used for PA assessment. Other research conducted by Lubans et al. [30] refers to the estimated $\mathrm{VO}_{2}$ max. This study examined the relationship between pedometer step counts and estimated $\mathrm{VO}_{2}$ max as determined by a submaximal exercise test. The results of that study suggest that estimated $\mathrm{VO}_{2}$ max is moderately associated with mean steps per day in adolescents.

The results obtained in the present study also indicate a lack of significant differences in psychological variables between girls from low active, slightly active and active groups. These results are inconsistent with the results obtained in other studies. However, the reported associations between psychological variables and the level of PA usually concerned PA measured through questionnaires or accelerometers, not pedometers which allow assessing only step counts. Research on self-efficacy, body image and self-esteem in 15-year-olds Polish adolescents in the context of PA was carried out by Kołoło et al. [31]. The study showed that psychological variables (selfefficacy, body image, physical self-esteem) are the determinants of PA. Research by Taverno et al. [29] indicated that highly active girls scored higher on self-efficacy, enjoyment of PA, selfmanagement strategies, outcome expectancy value, and support from family and friends than lowactive girls. A positive relationship between body satisfaction and PA amongst adolescents was observed by Finne et al. [32] and Frost, \& McKelvie [33]. However, Neumark-Sztainer et al. [34] found no relationship between body satisfaction and the PA level in girls.

According to daily step counts, three groups of girls were distinguished. As noted above, because of the lack of data, no groups with basal activity $(<2,500$ steps/day), limited activity (2,500-4,999 steps/day) and high activity ( $\geq 12,500$ steps/day) were analyzed. The relatively small range of the number of steps could be the reason for the lack of differences in the analyzed vari- 
ables, both psychological and biological. It can be assumed that the number of steps performed even by girls from the active group $(M=12,413.7)$ was too low to show beneficial relationships with psychological and biological variables. Some existing recommendations on the number of steps in children and adolescents are even 15,000-16,000 steps per day [35]. Perhaps such high values of daily step counts are related to better biological and psychological variables.

This study has several strengths and limitations. Pedometers have been found to be a reliable instrument for measuring walking-type movements, which might be considered a strength. One of the limitations of the study could the relatively small sample size. Girls participating in the study were volunteers which could have a bias effect on the final results. Additionally the psychological variables were calculated using the self-assessment method, that relies on the subjective interpretation of the questions being asked.

\section{Conclusions}

No differences in psychological and biological variables have been found among girls characterized as low active, slightly active and active. It should be noted that girls in the study performed approximately between 5,000 to 12,500 steps a day. To explain the relationship between daily step counts and psychological and biological variables better, future research should additionally account for girls with less than 5,000 steps per day and more than 12,500 steps per day.

\section{References}

1. Vouri I. Physical inactivity is a cause and physical activity is a remedy for major public health problems. Kinesiology. 2004;36(2):123-153.

2. Kang M, Marshall SJ, Barreira TV, Lee JO. Effect of pedometer-based physical activity interventions: a meta-analysis. Res Q Exerc Sport 2009;80(3):648-655.

3. Ball GD, McCargar LJ. Childhood obesity in Canada: A review of prevalence estimates and risk factors for cardiovascular diseases and type 2 diabetes. Can J Appl Physiol. 2003;28(1):117-140.

4. Duncan EK, Scott DJ, Schofield G. Pedometer-determined physical activity and active transport in girls. Int J Behav Nutr Phys Act. 2008;5:2. doi: 10.1186/1479-5868-5-2.

5. Jakobik K, et al., editors. Zdrowie dzieci i mlodziezy w Polsce [Health of children and youth in Poland in 2009]. Krakow: Glowny Urzad Statystyczny, Urzad Statystyczny w Krakowie; 2011. Polish.

6. Mazur J, Malkowska-Szkutnik A, editors. Wyniki badań HBSC 2010. Raport techniczny [Results of HBSC 2010. Technical Report], Warszawa: IMID; 2011. Polish.

7. Ogden $\mathrm{CL}$, Flegal KM, Carroll MD, Johnson CL. Prevalence and trends in overweight among US children and adolescents. JAMA. 2002;288(14):1728-1732.

8. Hill JO, Melanson EL. Overview of the determinants of overweight and obesity: current evidence and research issues. Med Sci Sports Exerc. 1999;31(11 Suppl):S515-S521.

9. Ross R, Janssen I. Physical activity, total and regional obesity: dose-response considerations. Med Sci Sports Exerc. 2001;33(6 Suppl):S521-S529.

10. Van Der Horst K, Paw MJ, Twisk JW, Van Mechelen W. A brief review on correlates of physical activity and sedentariness in youth. Med Sci Sports Exerc. 2007;39(8):1241-50.

11. DuVall C, Dinger MK, Taylor EL, Bemben D. Minimal-contact physical activity interventions in women: a pilot study. Am J Health Behav. 2004;28(3):280-286.

12. Tudor-Locke C, Bassett DR Jr. How many steps/day are enough? Preliminary pedometer indices for public health. Sports Med. 2004;34(1):1-8.

13. Tudor-Locke C, Hatano Y, Pangrazi RP, Kang M. Revisiting "How many steps are enough?" Med Sci Sports Exerc. 2008;40(7Suppl):S537-S543.

14. World Health Organization. Global recommendation on physical activity for health. Switzerland, Geneva: WHO Press; 2010.

15. EU Physical Activity Guidelines. Recommended policy actions in support of health-enhancing physical activity. Fourth consolidated draft, approved by the EU Working Group "Sport \& Health", Brussels; 2008. [Available at: http://ec.europa.eu/sport/library/doc/c1/pa_guidelines_4th_consolidated_draft_en.pdf] [Accessed June 20, 2011].

16. Le Masurier GC, Beighle A, Corbin CB, et al. Pedometer-determined physical activity levels of youth. $J$ Phys Act Health. 2005;2:159-168.

17. Duncan JS, Schofield G, Duncan EK. Pedometer-determined physical activity and body composition in New Zealand children. Med Sci Sports Exerc. 2006;38(8):1402-1409. 
18. Novakova Lokvencova P, Fromel K, Chmelík F, Groffik D, Bebcakova V. School and weekend physical activity of 15-16 year-old Czech, Slovak and Polish adolescents. Acta Univ Palacki Olomuc, Gymn. 2011;41(3):39-45.

19. Groffik D, Fromel K, Pelclova J. Pedometers as a method for modification of physical activity in students. J Hum Kinet. 2008; 20:131-137.

20. U.S. Department of Health and Human Services. Physical Activity and Health: A Report of the Surgeon General. Atlanta, GA: U.S. Department of Health and Human Services, Centers for Disease Control and Prevention, National Center for Chronic Disease Prevention and Health Promotion; 1996.

21. Campbell A, Hausenblas HA. Effects of exercise interventions on body image: A meta-analysis. $J$ Health Psychol. 2009; 14(6): 780-793.

22. Kline GM, Porcari JP, Hintermeister R, et al. Estimation of VO2max from a one-mile track walk, gender, age, and body weight. Med Sci Sports Exerc. 1987;19(3):253-259.

23. McSwegin PJ, Plowman SA, Wolff GM, Guttenberg GL. The validity of a one-mile walk test for high school age individuals. Meas Phys Educ Exerc Sci. 1998;2(1):47-63.

24. Motl RW, Dishman RK, Trost SG, et al. Factorial validity and invariance of questionnaires measuring social-cognitive determinants of physical activity among adolescent girls. Prev Med. 2000;31(5):584-94.

25. Motl RW, Dishman RK, Saunders R, Dowda M, Felton G, Pate RR. Measuring enjoyment of physical activity in adolescent girls. Am J Prev Med. 2001;21(2):110-117.

26. Orbach I, Mikulincer M. The body investment scale: Construction and validation of a body experiences scale. Psychol Assessment. 1998;10(4):415-425.

27. Samir N, Mahmud S, Khuwaja AK. Prevalence of physical inactivity and barriers to physical activity among obese attendants at a community health-care center in Karachi, Pakistan. BMC Res Notes. 2011;4:174.

28. Cuddihy T, Tomson LM, Jonston K, Johnston AO. Exploring the relationship between daily steps, body mass index and physical self-esteem in female Australian adolescents. JESF. 2006; 4(1):25-35.

29. Taverno Ross SE, Dowda M, Beets MW, Pate RR. Physical activity behavior and related characteristics of highly active eighth-grade girls. J Adolesc Health. 2013. doi: 10.1016/j.jadohealth.2012.12.003. [Epub ahead of print].

30. Lubans D, Philip M, Callister R, Collis CE. The relationship between pedometer step counts and estimated VO2 max as determined by a submaximal fitness test in adolescents. Pediatr Exerc Sci. 2008; 20(3):273-284.

31. Kololo H, Guszkowska M, Mazur J, Dzielska A. Self-efficacy, self-esteem and body image as psychological determinants of 15-year-old adolescents' physical activity levels. Hum Mov.2012;13(3):264-270.

32. Finne E, Bucksch J, Lampert T, Kolip P. Age, puberty, body dissatisfaction, and physical activity decline in adolescents. Results of the German Health Interview and Examination Survey (KiGGS). Int J Behav Nutr Phys Act. 2011;8:119. doi:10.1186/1479-5868-8-119.

33. Frost J, McKelvie SJ. The relationship of self-esteem and body satisfaction to exercise activity for male and female elementary school, high school, and university students. Athl Insight. 2005;7(4):36-49.

34. Neumark-Sztainer D, Goeden C, Story M, Wall M. Associations between body satisfaction and physical activity in adolescents: implications for programs aimed at preventing a broad spectrum of weight-related disorders. Eat Disord. 2004;12(2):125-137.

35. Tudor-Locke C, Craig CL, Beets MW, et al. How many steps/day are enough? for children and adolescents. Int J Behav Nutr Phys Act. 2011;8:78. 